neither (a) nor (b) exhibits adherence to skin nor enlarged lymphatic glands in the axilla.

2. It is difficult for women, who are so accustomed to pain, to associate it with pathological lesions in their breasts. They do not regard pain in their breasts as being so important as when it occurs elsewhere. At puberty they experience mammary pain, which is repeated throughout the term of their menstrual periods. Any irregularity of the pelvic visceral organs induces pain in the breast. Various emotions. may give rise to it. Thus throughout life a certain amount of pain in the breasts is so common that many women regard it as a normal experience. The fact makes difficult an attempt to elicit pain as part of the history of a pathological lesion. In the report issued by the Ministry of Health, Dr. Lane-Claypon and Professor Major Greenwood, after studying *many histories of carcinoma of the breast, made a special point of stating that pain was a late symptom. If ordinary histories of patients can be trusted, the conclusion of this report is true. It is rare for a patient to state spontaneously that she had noticed any particular pain before she felt the lump in the breast. On the other hand, if a history be carefully taken and a special point be made of asking the patient to try and remember when she noticed a pain in the breast to which she was not accustomed, she will often say, "Oh, well, I did notice a little stabbing pain, but I did not take any notice of it." That is a common experience of mine, and I believe pain of this lancinating, stabbing character is often the earliest symptom of carcinoma of the breast, and the want of knowledge and appreciation of its importance on the part of the patient allows this important sign to be lost. The earliest carcinoma of the breast which I have excised was removed from a patient whose only complaint was a stabbing pain situated in one part of the breast. I could feel no lump or nodularity. I told her frankly that I could not find a cause for the pain, but that as there was about half an inch of fat between my fingers and the site of pain I could not be sure there was no cause. I said to her that her life might depend on whether a cause existed or not, and that I could not be sure about the matter until $I$ had removed that portion of the breast and had examined it microscopically. This was done, and on microscopical examination we discovered a small focus of carcinoma which was already beginning to spread into the fat surrounding the periphery of the gland. Since that case I have always regarded the presence of a lancinating pain situated in one part of a breast as a very important symptom, whether there is or is not a lump or nodularity to be felt.

3. A spontaneous intermittent discharge of blood from a nipple. By a spontaneous discharge of blood I mean a discharge not caused by trauma. A spontaneous discharge of blood from a nipple may be due to duct carcinoma, to carcinoma arising deep in the breasts in terminal ducts and acini, but also to papillomata, and very frequently the discharge oucurs (from these causes) when neither lump nor nodularity can be felt. Occasionally a papilloma in one ampulla may be the only tumour in the breast. On the other hand, a duct may contain hundreds of them situated throughout the whole of its course. Again, two or more papillomata may exist not in an ampulla at all, but in deeper parts of the breast. There is no clinical information to guide us as to whether there is only one papiloma in an ampulla, or whether there are multiple papillomata in the breast. Papillomata in a duct are as dangerous as in the large intestine; they are often associated with carcinoma.

4. Spontaneous discharge of serum "from the nipple may be caused by the same diseases that induce haemorrhage from the nipple, and should be regarded with the same degree of seriousness.

5. A gradually retracting nipple.

When any one of these signs exists it should be taken as a signal of danger. A lump or nodularity should be widely excised and microscopically examined. The same treatment should be applied to a part in which there is a loeal focus of pain. The whole breast should be excised as for carcinoma when there is spontaneous discharge of blood or serum from tho nipple. Lives are being lost by disregarding the importance of these early signs.
All thess surgeons who think they are giving important educational information to the public have made a great poin they notice a lump in their breast. Let us consider what are the implications of that advice so sincerely given. It implies that the patient is securing treatment early in the disease, whereas really, when a lump appears in carcinoma the disease-is well advanced, and is already threatening the patiert's life, possibly beyond all hope of a cure. A woman with that advice in her mind may feel a pain, see a discharge of blood or serum from her nipple, think that these are unimportant because she can feel no lump, and that therefore it is unnecessary to consult a doctor. The attempt to educate the public to become acute clinical observers is very praiseworthy, and if I were deeply impressed with its advisability I would make a great point of telling women that it is more essential that we should see their breasts beforo any lump has appeared. We want to see their breasts if they have either local nodularity or lancinating pain in one spot, or a discharge of blood, or a discharge of serum from the nipples. In any event we have no chance of abtaining better results after the operation for carcinoma of the breast unless we are able to attack the disease in an carlier state than we do at present.

\section{An Aànress}

ox

\section{ACROMEGALY FROM A SURGICAL STANDPOINT.}

HARVEY CUSHING,

PROFESSOZ OF SURGERY, TIE HARVARD MEDICAL SCHOOK. (With Special Plate.)

PART II.

\section{HYPER PITUITARISM.}

Th1 only clinical evidence we have of pituitary overactivity is overgrowth. That this overgrowth is due to excess, rather than to perversion of glandular function as. was long thought possible, has now been conclusively shown, not only by Evans's experiments; but by Smith's demonstration that homoplastic transplants will restore the normal curve of growth to rats which have been dwarfed by hypophysectomy.

As with clinical hypopituitarism, so with clinical hyperpituitarism, it is convenient to divide the cases into two main categories-those in which the disorder has set in during pre-adolescence, and those in which it has begun to manifest itself in adult life. The former results in gigantism, the latter in acromegaly. So far as is known, both of these states are invariably associated with a hyperplasia or, more commonly, with an actual adenoma of the chromophilic elements.

\section{The Chromophile Adenomas Originating in Pre-adolescence (Gigantism).}

It has come to be generally assumed that the difference between gigantism and acromegaly is merely one of difference in the age of onset. Accordingly, though giants and acromegalics differ to an extraordinary degree outwardly, this is held to be largely a matter of the skeletal response to the growth hormone; inwardly the consequences of the hyperpituitarism are much the same in the two maladies. Both are accompanied by visceral splanchnomegaly and by a hyperplasia, often with adenomatosis of the thyroid and parathyroid glands and adrenal cortex.

To be sure, these are clinico-pathological assumptions for which as yet there is no experimental proof. So far gigantism has only been reproduced in the rat, and since the interruption of oestrus serves as an indicator of the activity of the prepared extract, the female rat has commonly been used. Moreover, the rat is an animal whose epiphyses never close, so that its capacity for growth in length is unaltered throughout life. One would assume, therefore, that parenteral injections of anterior lobe extract would accelerate a rat's growth at any time of life, and 

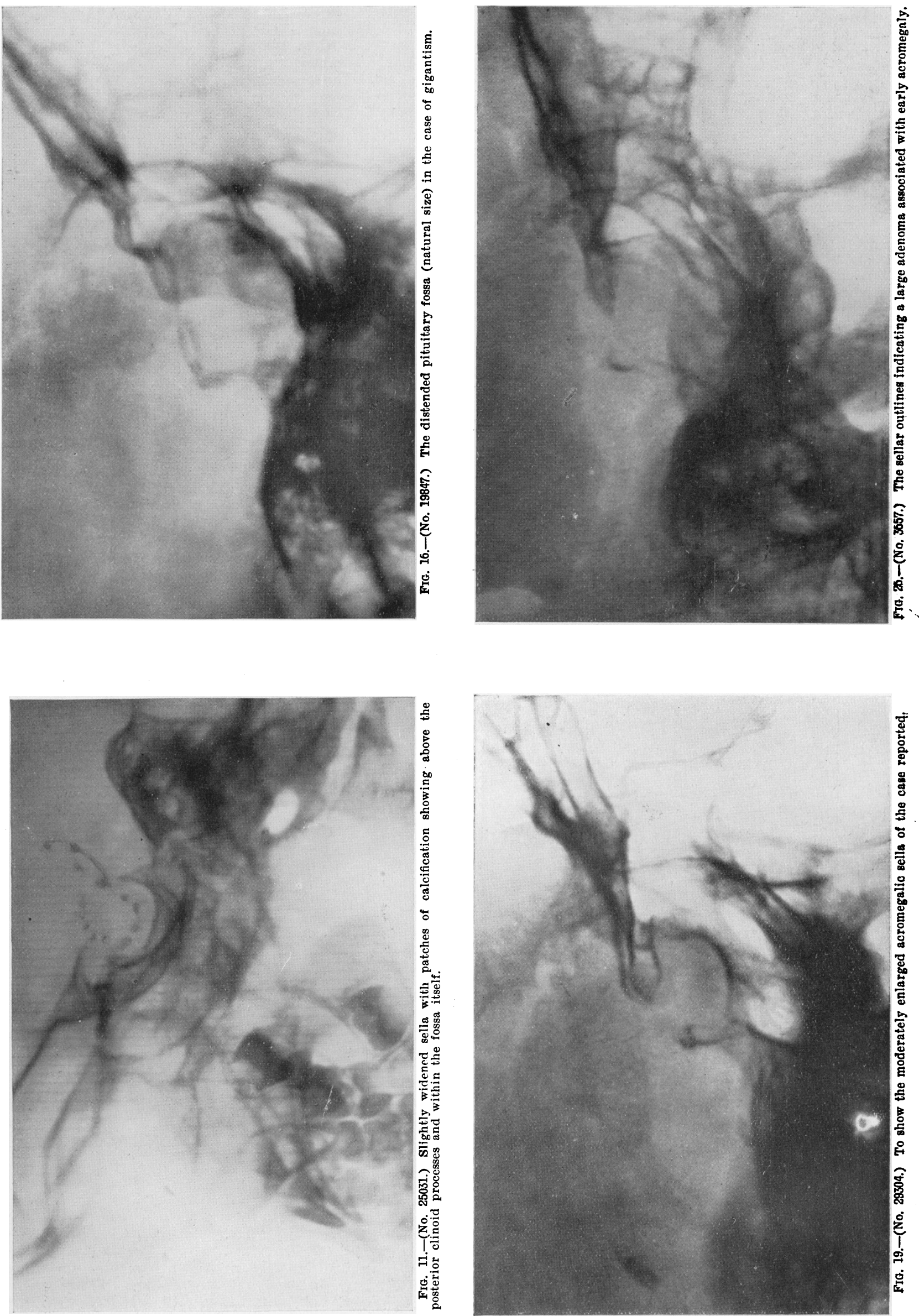

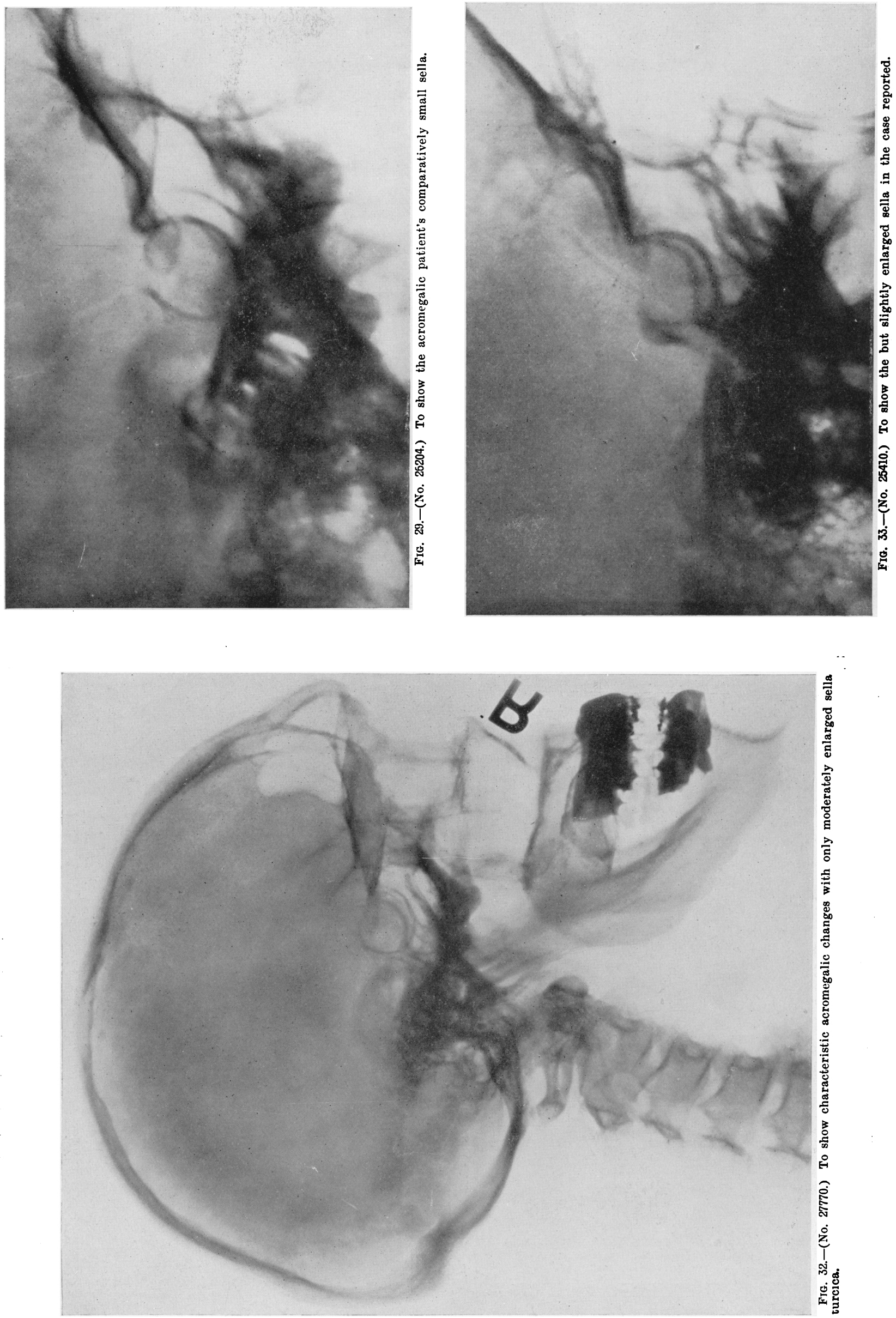
that something comparable to acromegaly could only be produced in animals whose epiphyses normally become closed.

Since both acromegaly and gigantism are inevitably associated with a chromophile adenoma ${ }^{8}$ (our present series of 65 verified cases all having shown an excess of this type of cell), and since a tendency to adenoma formation, whether chromophobe or chromophile, characterizes adult life, giants or acromegalic giants are much more rare than are cases of acromegaly. In other words, a pre-adolescent chromophile adenoma resulting in hyperpituitarism is about as rare as a pre-adolescent chromophobe adenoma resulting in hypopituitarism. Pituitary nanism, though a common malady, is usually due to lesions of other sorts.

In Davidoff's analysis of a consecutive series of 100 cases there were no examples of true gigantism; and though in a few of the patients the disease had started early enough to lead to an increase in stature, possibly only one of them might be considered to be an actual giant who possessed no acromegalic features. ${ }^{*}$

(Surg. No. 19847.) A young man (Fig. 15), a normally proportioned individual, had begun to grow rapidly at the age of 13 and at the time of his admission to hospital, when 21 years of age, he had attained a height of $6 \mathrm{ft}$. 8 in.

For a year he had had headaches, and the radiugraph showed a widely distended sella (Fig. 16). In view of the fact that there. was no evidence of pressure involvement against the chiasm, deep radiotherapy was advised and for a time he experienced subjective relief. - However, after his fourth radiation he had a severe generalized headache and soon noticed that his sight was failing. He experienced, to to 0 an extraordinary sense of muscular, weakness, became seriously ill, and was readmitted to the hospital because of was readmitted to the hospital because of
these symptoms. He was kept under observation for a time, but as his vision became reduced to blindness in one eye and a temporal hemianopsia in the other, surgical intervention seemed imperative.

In the course of the usual transphenoidal operation, on incising the dura over his huge tumour, soft, semi-liquefied tissue began to extrude, and what appeared to be a largely

necrotic adenoma was scooped away.

After operation there was prompt relief from headaches, and within seven days his visual fields had been restored almost to their normal peripheries; but it was long before he regained his general vigour. Convalescence was signalized by an extraordinary period of polyphagia, during which he was hardly satisfied with five large meals' a day $\mathrm{He}$. has since regained apparently normal health and has been leading an active lire on a ranch.

sections of the tissue showed a typical chromophile adenoma.

This case, then, has clinical resemblances to experimental gigantism, and it is hoped, in view of the radical removal of an adenoma seriously damaged by deep radiation, that a therapeutic cure of the process has been brought about. But he will always, of course, remain a giant, just as the giant rats of the experimental laboratory remain gigantic, eyen though further injections of anterior lobe extract are withdrawn.

\section{The Chromophilic Adenomas of Adult Life} (Acromegaly).

Acromegalic growth in the long run is so obvious that the clinical diagnosis is made at a glance. Nature in her ugliest mood conceived such a malady. To heap insult on injury, its victims often suffer from intolerable headaches, dire presumably to the participation of the sella in the general osseous overgrowth, so that its walls give way less easily than do those which enclose the ordinary chromophobe adenomas. Otherwise, the cephalalgia of hypopituitary cases would be equally severe, which it is not; for when the more easily distensible pituitary fossa in these states has expanded, the headaches usually cease.

But even in acromegaly the fossa gives way in time, and the-adenoma may eventually rupture the enveloping capsule and fill the. sphenoidal cells, or, what is worse, push its way into the cranial chamber. In proportion to the number of cases, more extreme instances of this latter

* The case was included in the report by Dott and Bailey, loc. cit. eventuality have been met with in acromegalics than in patients with the more common chromophobe tumours. I. may be permitted to borrow a telling example from a recent monograph in which the nature of these pituitary tumours was. discussed. ${ }^{9}$

The illustrations (Figs. 17 and 18) serve to show how in this particular case the unmistakably adenomatous lesion, having passed laterally through the capsule, has developed unrestricted in the cranial chamber, leaving the remainder of the fairly intact gland in a relatively small sella. The patient, who had long suffered from acromegalic diabetes, ultimately died from acute cardiac failure associated with a cor bovinum-a not uncommon ending for severe cases of acromegaly. During his life not the slightest suspicion of this huge intracranial extension of the growth had been aroused. Could it have been recognized, it might well enough have been attacked even in its advanced state. But the only possible way to have checked the patient's malady, as something apart from the tumour problem, would have been by an early extirpation of the lesion before the disastrous secondary effects of his long-standing hyperpituitarism, of which the cardiac hypertrophy was part and parcel, had cccurred.

A chromophile adenoma, however, has usually announced itself by Marie's unmistakab!e syndrome long before the gland shows any noticeable enlargement, and consequently beforè the sella has become distended. This was one of the reasons for the doubts formerly expressed as to whether the pituitary tumour was a carsal or coincidental lesion in acromegaly. We know better than that to-day; but the point I would emphasize is that a small hypophysis may accompany unmistakable acromegaly, whereas in the hypopituitary states produced by chromephobe adenomas, the secondary constitutional disturbances are so relatively inconspicuous that the disorder is not likely to be recognized until the tumour lias reached a size sufficient to provoke the characteristic neighbourhood symptoms. In other words, the tumour is what calls attention to adult hypopituitarism; whereas acromegaly calls attention to jtself before the adenoma has reached the tumefaction stage.

These things being so, are we entitled to attack a chromophile adenoma while small in the hope of forestalling its future devastating effects on the body? This is the rub, and though another generation will have to answer the question practically, we are at least entitled to consider it theoretically.

Heretofore, in the long run of cases, the surgical problem in acromegaly has been no different from that in pituitary insufficiency due to chromophobe adenomas. When a pituitary tumour, regardless of its cytological composition, becomes large enough to distort-the chiasm and to impair vision, the problem clearly is one to be met by mechanical (surgical) measures. The surgeon's objective accordingly is to remove, by whatever method he particularly favours, a sufficient amount of the growth to relieve the chiasm from pressure; and the results, so far as restoration of vision is concerned, have been equally good whatever the composition of the adenoma-purely chromophile, transitional, or purely chromophobe.

It may be well at this point to give an illustration of what we would heretofore have looked upon as a suffciently creditable outcome of one of these operations. For the purposes of my theme I shall select a fifteen-year-old example.

(Surg. No. 29304.) A Russian, aged 23 years, was admitted to the Johns Hopkins Hospital on February 19th, 1912. His complaints, as recorded, consisted of severe headaches with photophobia, enlargement of the extremities, and impotence-all of about four years' duration. In the preceding three years his weight had increased from 160 to $191 \mathrm{lb}$. His acromegaly was fairly pronounced (Figs. 20,21), and in spite of his comparative 
youth was unassociated with traces of gigantism, his height $(5 \mathrm{ft} 9.1 \mathrm{e}$ in.) having remained stationary. The sella was serious involrement of the chiasm intervention was postponed.

He re-entered the hospital a month later, owing to a great zccentuation of his headaches, which had become incapacitating. A bitemporal constriction of the visual fields, with beginning pallor of the optic nerves, had by this time become sufficiently avident to justify intervention on this score alone. Accordingly on March 16th, 1912, by the usual transphenoidal procedure, the bulging sella, its base partly absorbed by pressure, was brought to view. On incising the tense dural capsule, soft tumour began to extrude itself, and, for the day, a fairly generous amount of the adenomatous tissue was scooped out. This afforded immediate and complete relief from the headache, normal visual field peripheries were restored, and he was discharged happy.

The patient was lost sight of until November 6th, 1920 (eight years later), when, in response to a letter of inquiry, he reported in person to inquire whether a plastic resection of his jaw might not restore the alignment of his teeth and at the same time improve his appearance. Apart from his increasing prognathism (Figs. 22, 23), he felt content with his lot, for he had had no headaches or disturbance of vision since his operation, his sexual vigour had been restored, his general health was perfect, and he had been able to keep steadily at work. Nevertheless, the malady was evidently progressing. His weight had increased to $228 \mathrm{lb}$, and for two years he had shown a moderate glycosuria, which had been kept under control by dietary restrictions.

Recently, on May 18th, 1927, he again reported, on request, for further examination, fifteen years having elapsed since his opera-
tion. During this long period he has been notably exempt from the distressing waves of inertia and drowsiness from which acromegalics often suffer. There have been no headaches whatsoever, and vision remains unimpaired. He has been sufficiently succossful in business to justify his marriage eighteen months

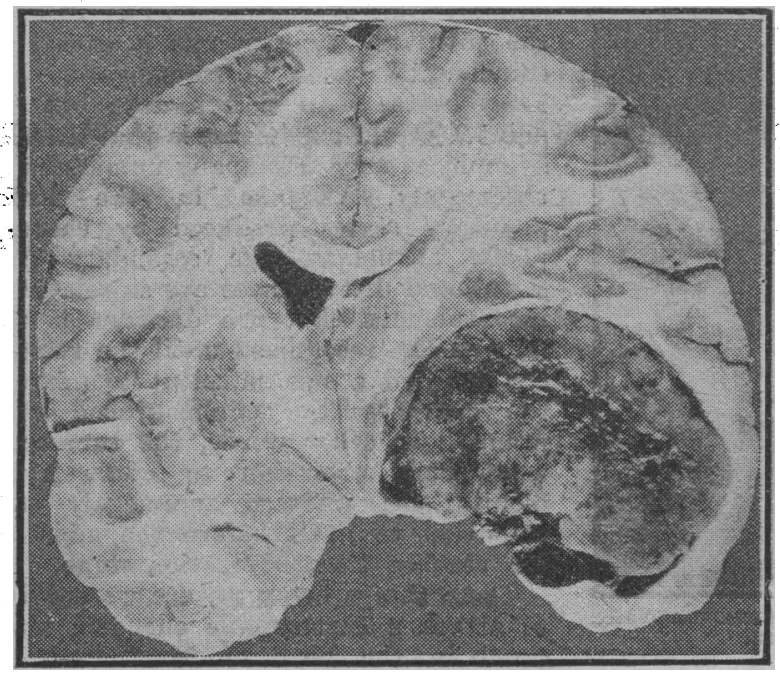

Frg. 17.- Showing large, unsuspected, and symptomless intra-
cranial extension of a chromophile adenoma in a case of acromegaly.

ago, and he is the proud father of a healthy son 4 months of age. In spite of all these fávourable signs, his acromegalic manifestations have slowty progressed (Figs. 24, 25). His weight has increased to $245 \mathrm{lb}$; ; his glycosuria persists; and with the further enlargement of the acral parts, his mandibular arch has become so enormous that dental occlusion is completely lost and the jaw when closed rides up to his nose.

From the standpoint of the tumour symptoms, taken by themselves, this would seem to be a sufficiently favourable end-result. But in the present state of our knowledge, may wo not look forward to accomplishing something more for similar cases? A sufficient number of observations have been accumulated to justify an affrmative answer to this question, for they tend to show that the secondary constitutional expressions of hyperpituitarism, as something apart from its tumour effects, may be considerably ameliorated by surgical procedures.

Thero is, to be sure, nothing novel about this. In the first recorded operation upon an hypophyseal tumour associated with acromegaly Hochenegg observed a striking postoperative shrinkage in the tissues; and the same phenomenon was noted in my-first case, operated upon shortly afterward:10

The patient was a man, aged 38 years, with outspoken acromegaly of eight years' standing, who was victimized by severe and persistent cephalalgia. Under the assumption that his discomforts were due to distension of thé sensitive glandular capsule, it was hoped that the mere " decompression" of the sella might serve to palliate them. However, with the enlarged gland well exposed, I succumbed to the temptation to remove a considerable portion of it, and not only, to my gratification, were the man's headaches promptly relieved, but, to my surprise, there was a striking and unexpected post-operative change in the appearance of the patient's face and extremities. This was due, apparently, to the shrinkage of the previously boggy subcutaneous tissues, which left the skin supple and finely wrinkled.

In retrospect $I$ feel that insufficient importance was laid upon the significance of this early observation, but, as a matter of fact, during the next several rears, while the complicated technique employed in this first case was being simplified, attention was chiefly paid to combating tumour symptoms produced by the far more common alenomas of the chromophobe variety.

During this period patients with acromegaly were being

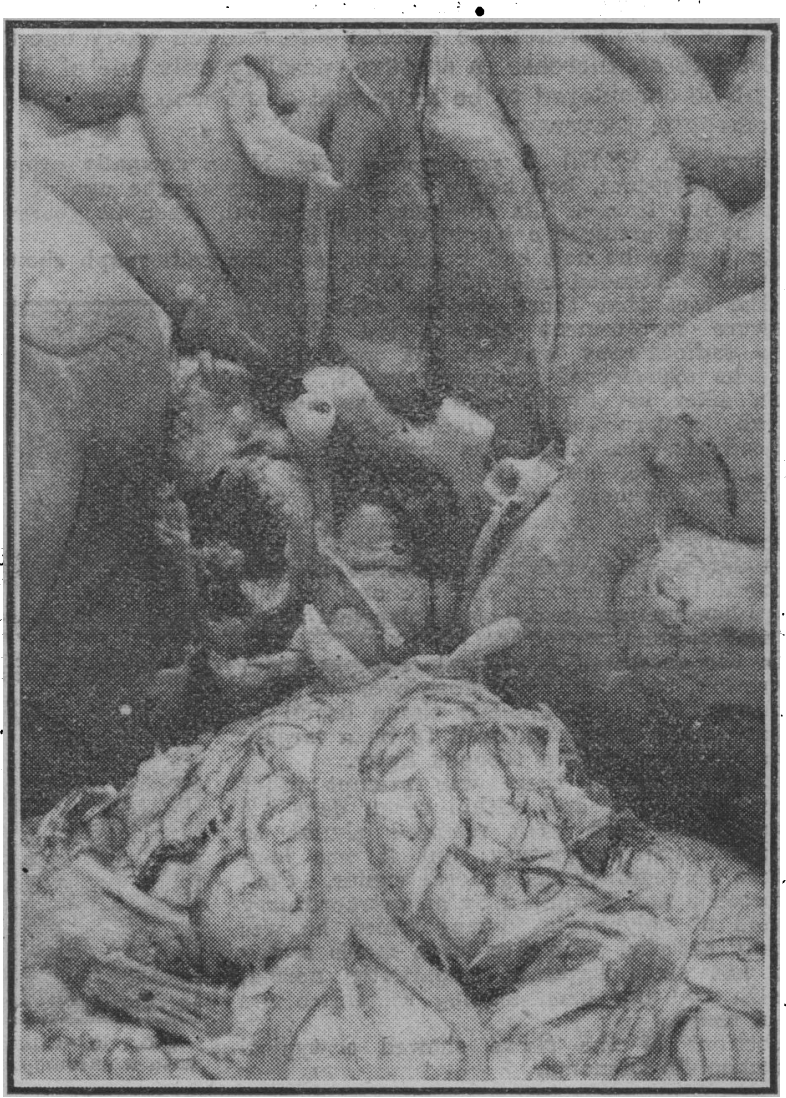
Fic. 18.- To show (natural size) the intrapeduncular space and
the broken neck of the laterally projecting adenoma. (Cf. Fig. 17.)

surgically treated on much the same basis, with the sole object of relieving local pressure symptoms, and only when the sella was greatly enlarged and vision was implicated. But from time to time, more by accident than intent, the operation was followed by an unexpected improvement in the "acromegalism" itself; and in an occasional case the progressive malady appeared to be actually checked. The following record may be given in illustration.

(Surg. No. 3657.) A married woman, aged 27, was admitted to the hospital on October 6th, 1915, and gave the following story. She had married in 1907 at the age of 19 , and a year later gave birth to a healthy child. Previously an active woman, she subsequently became drowsy, asthenic, susceptible to colds, experienced a loss of libido, and finally in 1912 became completely amenorrhoeic. Meanwhile her weight increased from 128 to $158 \mathrm{lb}$., and her hands got so puffy that her rings and gloves could not be worn. In course of time she began having dull headaches, and her visual acuity became impaired. Ere long a temporal constriction of the fields of vision became apparent, and the suspicion of a pituitary tumour was aroused.

In addition to the unmistakable clinical and roentgenological evidences of early acromegaly, the physical examination diselased a bitemporal hemianopsia and a sella considerably increased in size (Fig. 26). On the basis of these findings an operation was advised. Accordingly, on October 9th, 1915, by the usual transphenoidal approach the floor of the bulging sella was exposed, and considerable amount of adenomatous tissue, which proved to be chromophilic in character, was removed.

The operation was folowed by prompt improvement in vision with early re-establishment of normal field peripheries. But what 


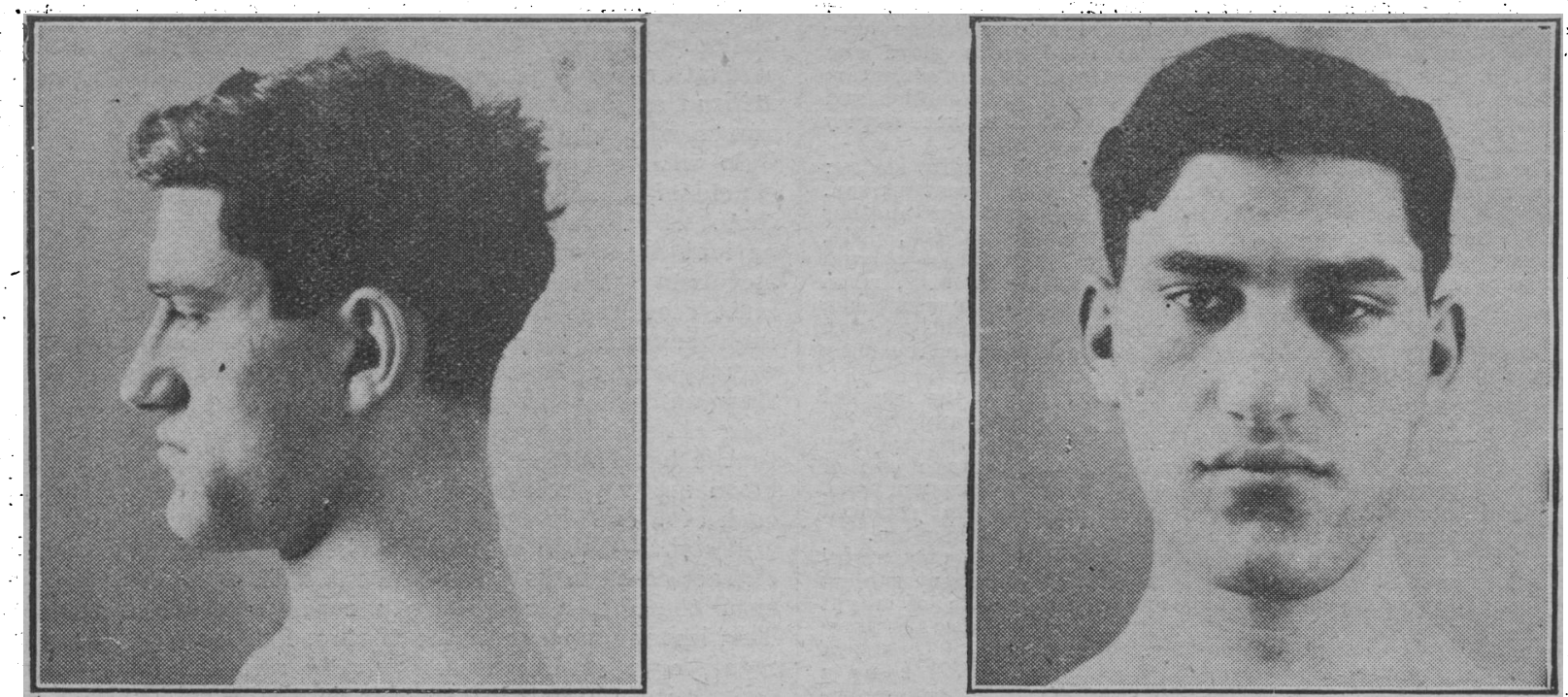

Figs. 20 AND 21.-(Case 29304.) Showing the patient's facial contours, March 13th, 1912, shortly before operation. Aged 23.years.
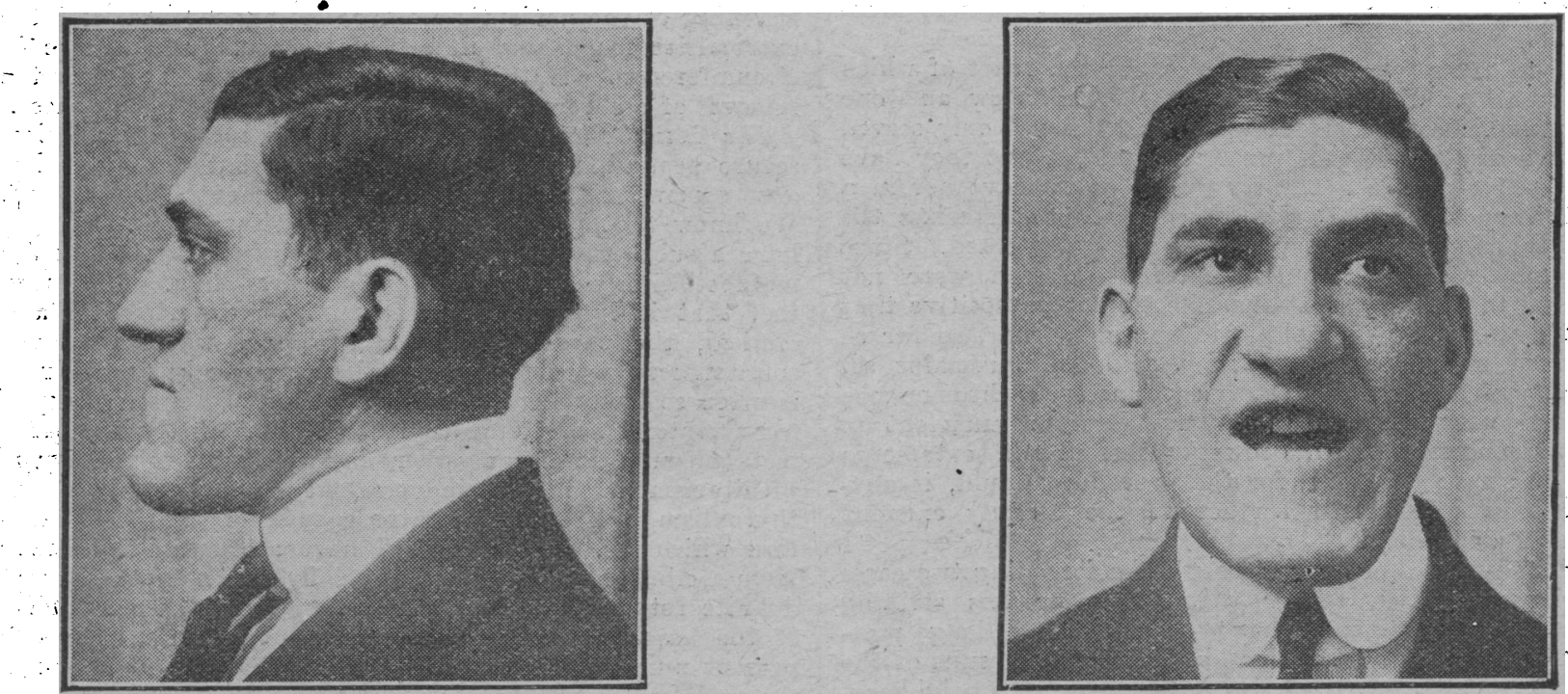

Figs. 22 AND 23.-(Case 29304.) Showing same patient eight years later (cf. Figs. 20 and 21) at the age of 31 years.
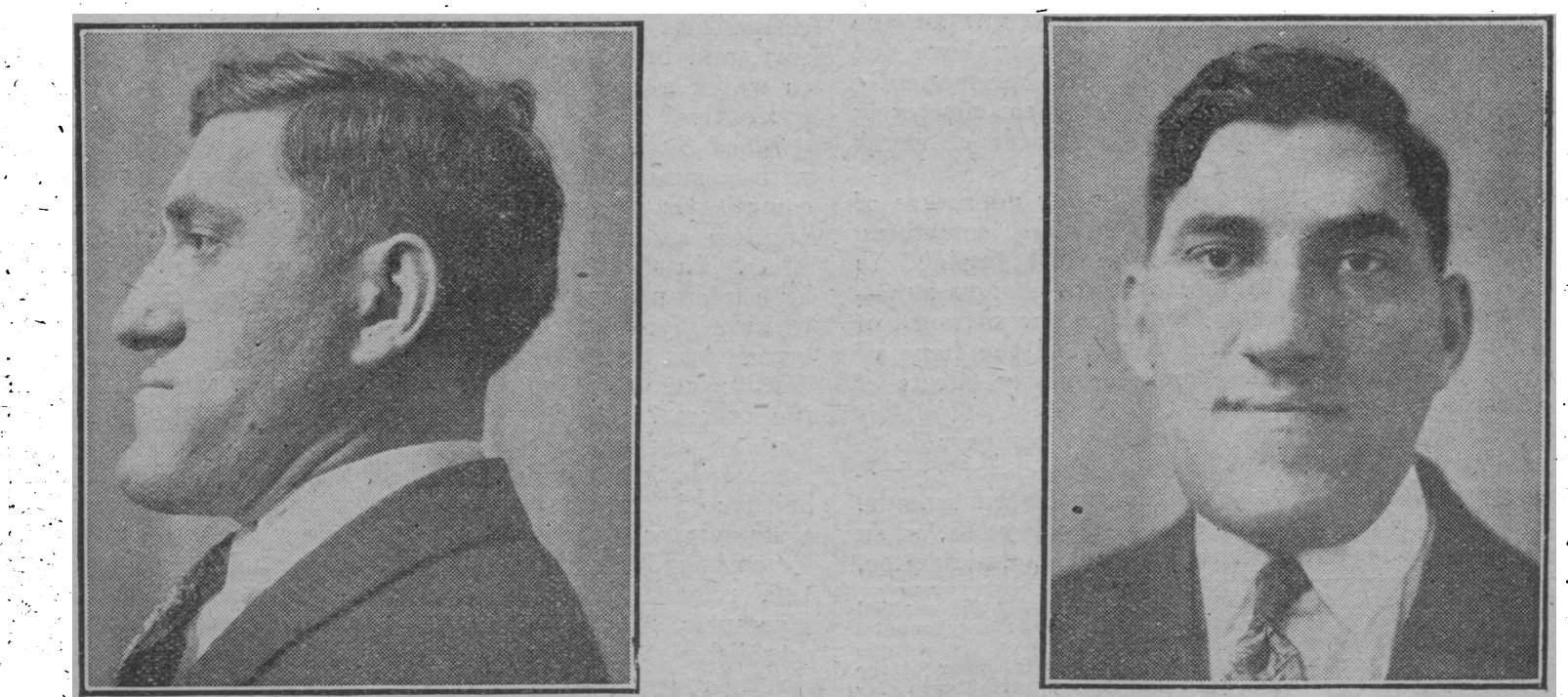

FiGs. $2 A$ aND 25.-(Case 29z01.) To show the patient's advancing deformity, after aftcen years, aged 38. Note the difference in comparative width of forehead and face in Figs. 25 and 21 . 
is more important in our present connexion is this bedside note of October $13 \mathrm{th}$, made by Dr. E. B. Towne, the house officer "The patient calls attention to the fact that her hands have become less puffy than before. She has tried on a glove and finds that it slips on more readily than usual. On examination it is evident that the skin of the dorsum has become wrinkled and that the previous thick and oedematous condition has largely disappeared." She was discharged on October 19th.

disappeared." She was discharged on October 19th. “I gain in strength each day and feel like a different person. My husband says that his wife has been changed for another woman." Subsequent notes state: that, on March 6th, 1916 after three years of complete amenorrhoea, normal menstrua periods were resumed and continued for seventeen months, when she became pregnant; that a healthy child was born which she nursed for eight months; that on weaning the child, though catamenia became re-established, the periods were increasingly catamenia became re-esta

In July, 1918, when I was overseas, she reported to the hospital that her vision was once more becoming impaired; and by the time of my return in April, 1919, a bitemporal hemianopsia was again present. As I did not feel inclined to undertake one of these operations at the time, she consulted another surgeon, who by a lateral osteoplastic cranial procedure, exposed and removed a pituitary tumour, said to have been the size of a wild plum.

Though this operation has served to restore permanently useful vision, which was its main object, it has left the patient subject to occasional convulsions, and apparently in a state of slight to occasional convulsions, and apparently in a state of slight pituitary insufficiency, in spite of which she continues to have occasional irregular menstrual periods. She is now 39 years of tendericy to adiposity. She has the unmistakable appearance of slight hypopituitarism, and a constantly subnormal: temperature; but she leads an active life and regards herself as reasonably well.

Here, then, was a woman with early symptoms of acromegaly, associated with a chromophilic adenoma large enough to cause pressure symptoms, for the relief of which two operations were performed, one from below and one from above. These consecutive procedures not only served their primary purpose of preserving vision, but they have so far overcome her hyperpituitarism as to leave her in a dyspituitary state similar to that which characterizes the adenomas of transitional typo previously discussed. Since the tissues removed at the second operation were not subjected to differential stains, one cannot be positive that the cells were still acidophilic in character, but, so far as is known, an adenoma primarily acidophilic remains so. Certainly after corresponding operations for a chromophobe adenoma, with a degree of hypopituitarism sufficient to cause amenorrhoea, the re-establishment of catamenia would not have occurred, for the procedure would, if anything, have added still further to the already existent glandular deficiency.

For the purpose of my argument, the foregoing two cases have been selected, rather than other no less striking exarnples, because they have a sufficiently long postoperative history to give some idea of the end-results of the surgical procedires. - Both had large seltas with neighbourhood symptoms, for which reason the surgical indrications wero clear. In the first case, one of well advanced acromegaly, the pressure symptoms have been permanently relieved, but the disease has slowly progressed. "In the second, an early case of acromegaly, not only have the pressure symptoms been to all appearances permanently offset, but the hyperpituitarism has been so effectively checked as indeed to be replaced by evidences of slight glandular deficiency.

Since the mortality of these operations for adenomas of all kinds and sizes has reached the low figure of something under 4 per cent., we have begun to feel justified in favourable cireumstances in taking the next obvious stepnamely, in making a direct, early attack on the adenoma of acromegaly while the sella is still small, in the hope of forestalling the oftentimes disastrous secondary effects of hyperpituitarism.

This step, I hardly need say, is precisely comparable to that which was taken to combat the effects of hyperthyroidism regardless of the size of the associated tumour. But oven in the less complicated case of the thyroid, when operations began to be undertaken for exophthalmic goitre,

* To May 1st, 1927, there have been in my entire series 264 verified adenomas with a total of 291 operations: 253 by a transphenoidal route with 17 fatalities (6.7 per cent.), and 38 by a transfrontal route
with 2 fatalities (5.0 per cent.). Owing to the operations in cases of acromegaly, the mortality difficulty of the chromophilic adenomas are slightly higher than for thercentages for variety. In the last 50 operations, inchuding both types, chromophobe mortality has'now been only 3.8 per cent. the largely subjective and impressionistic reports concerning them were not favourably received by a sceptical profession. Nor did they become really convincing until the estimation of the patient's basal metabolic rate was utilized as a more or less satisfactory means of registering numerically what had been accomplished.

So with operations for hyperpituitarism, the secondary effects of which are more complex and far-reaching than those of thyreotoxicosis, the mere statement that the patient has been subjectively improved" or that the "acromegalism" appears to be less marked is insufficient. We must reach out for some actual measure of the patient's improvement. - Meanwhile, in place of something better, we may take recourse in the following three factors, though they unfortunately are not applicable to all cases. They are: (1) the diminution in weight and size; (2) the change in the basal metabolic rate; and (3) the alteration in the blood sugar percentage. A word may be said concerning each of them.

Weight:- When the daily injections of anterior lobe extract cease to be given to a rat with experimental gigantism there is a surprisingly rapid loss of body weight. 'This loss must oceur in the tissues, for the skeletal enlargement, once attained, is naturally unalterable, or largely so. Quite comparable to this is the considerable loss of weight exhibited by acromegalic patients that follows upon the even partial removal of an acidophilic adenoma. Associated with this loss of weight there is often a distinct lessening of the patient's acromegalic appearance, and the extremities may show an actual measurable shrinkage in circumference. Nothing of this sort occurs after the removal of a chromophobe adenoma in hypopituitary cases.

The Basal Metabolic Rate.-Here we tread upon less secure ground, largely for the reason that the clinic has got somewhat ahead of the experimental laboratory. We know that patients with hypopituitary states tend to have a subnormal metabolism, whereas in acromegalics the metabolism is often (though not always) high. Wo know, too, that in hypopituitary states, both experimental and clinical, the thyreid gland is atrophic, whereas in the counterposed state represented by acromegaly the thyroid is often so hyperplastic that it may even be operated upon for symptoms suggesting thyreotoxicosis. Is the increased metabolism of acromegaly therefore ascribable to the hyperpituitarism or to an independent condition of hyperthyroidism, or are the two interdependent? This is a question which Dr. Davidoff and I have attempted to answer from a clinical standpoint, being fully aware that far more definite returns will some day be supplied through studies of the basal metabolism of hyperpituitary rats. For our present purposes it may suffice to say that, whether or not the increased metabolism in acromegaly is primarily of hypophyseal (which we believe it to be) or primarily of thyroid origin, it can be as definitely lowered by a partial hypophysectomy as by a partial thyroidectomy. Hence estimations of the basal metabolic rate may serve in some sort, and in suitable cases, as an indication of the degree to which a hypophysectomy has diminished the glandular overaction.

Blood Sugar Determination.-Here too we are eoncerned with a similar question which has to do with one of the complicated secondary effects of hypophyseal activity on another element in the endocrine series-the pancreatic islets. In the long run, hypopituitary patients exhibit a high tolerance for carbohydrates, whereas acromegalies tend to have glycosuria or even diabetes, which may be of such severity as to end in coma. Is this wholly and independently pancreatic, or does the hypophysis play some role in the process? To this question also we have attempted to give an answer. And though as yet we have no experimental confirmation of our clinical findings, it may be said, briefly: (1) that acromegalics, even in the absence of hyperglycaemia or glycosuria, tend to show a relative intolerance for carbohydrates; and (2) that by a partial hypophysectomy this relative intolerance may be reduced, an existent glycosuria may be checked, and even when diabetes is established the patient's susceptibility to the action of insulin appears to be increased.

By means of these three tests, then-by the shrinkage of hyperpituitary tissues, by the lowering of the metabolic 

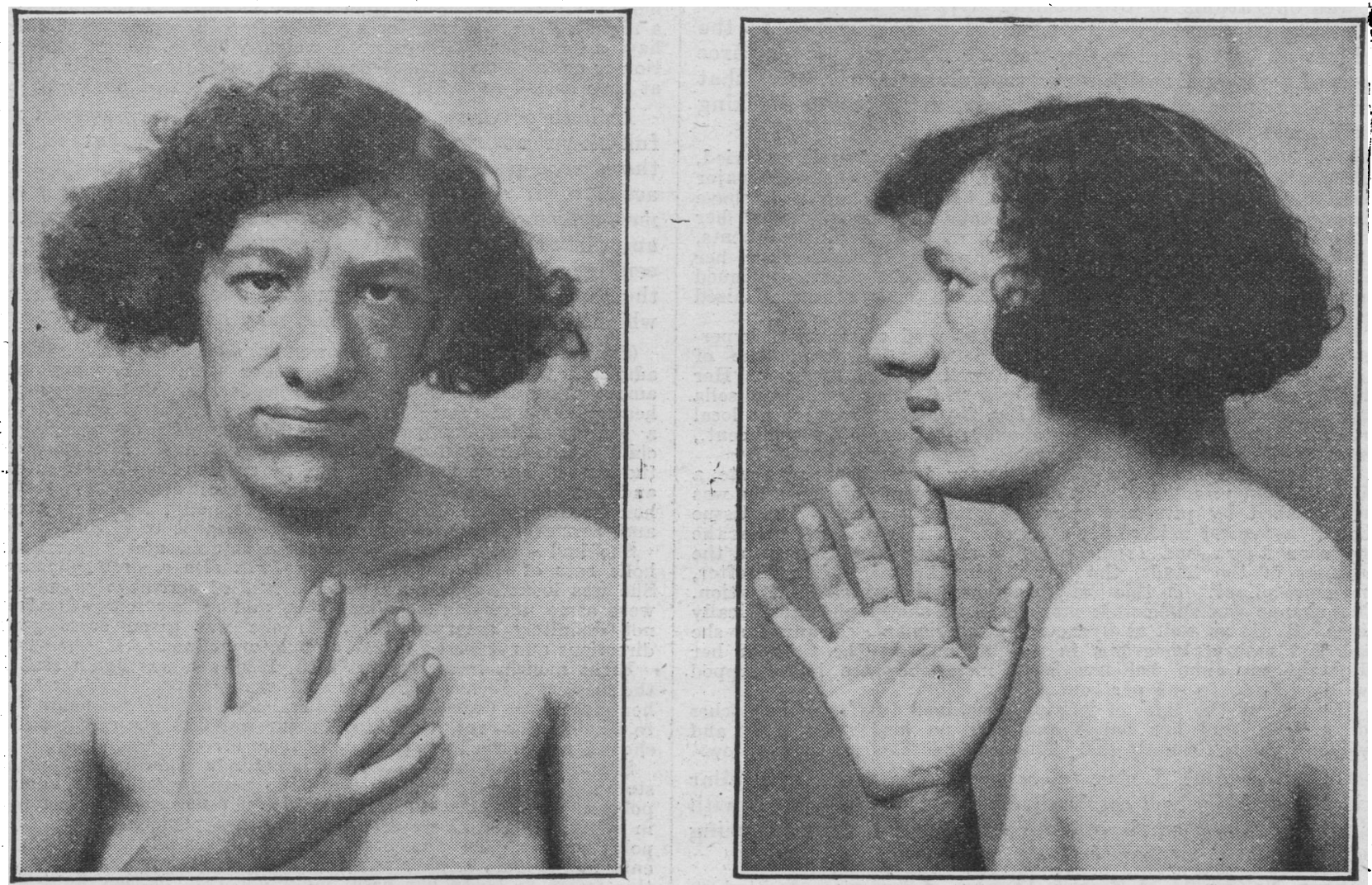

FIGS. 27 AND 28.-(No. 26204). Outspoken acromegaly associated with a comparatively small adenoma. (Cf. Fig. 29.)
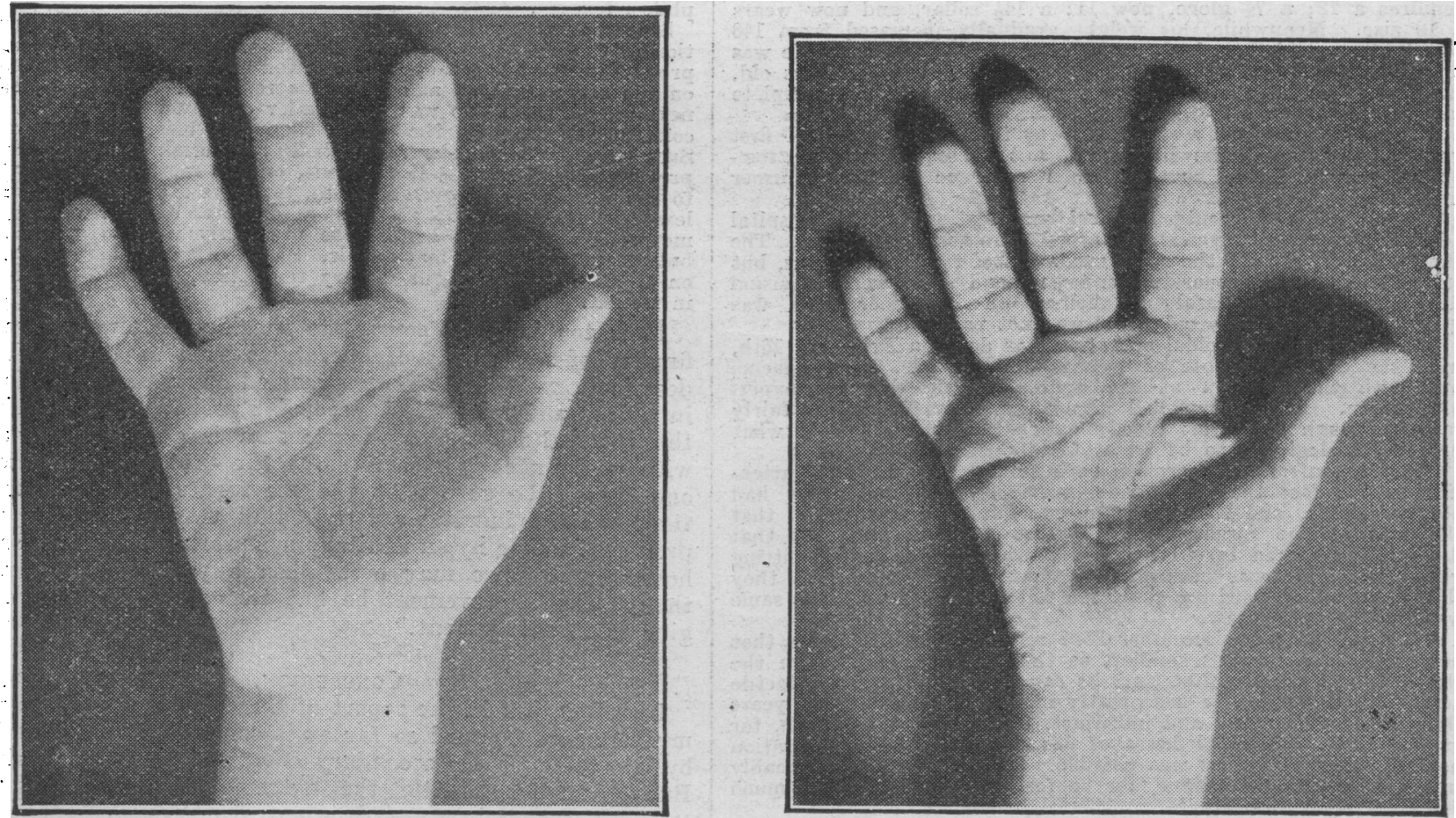
FIGs. 30 AND 31.-(No. 26204.) To show by the pre- and post-operative photographs of the patient's right hand the subsidence of the hyper- 
rate, and by an incrase in carbohydrate tolerance-we have at our disposal some measure, however crute, of the effect of our operations in diminishing hyperpituitarism. After this long explanatory digression let us now return to the subject at hand, and to the consideration of two or three cases of acromegaly with comparatively small adenomas that hare been operated upon with the primary ohject of checking the disease itself.

(Surg. No. 20204) A Russimn tailoress, 23 years of age, unmarried, was admitted to bespital on April 22nd, 1926, with the usual major complaint of severe headaches: She had been known to have acromegaly for a number of years, and on the advice of her physician she had been given a series of deep $x$-ray treatments, which late failed to alleviate her discomforts. Meanwhile he catamenia, which had set in at the age of 14 years, continued without interruption, though she bad become somewhat masculinized and, for her sex, extremely hirsute.

She haxt (Figs. 27, 28) the typical enlarged extremities, hyper. trophic nose, lips, and tongue of a fairly advanced case of acromegaly, and the spine showed a well marked kyphosis. Her height was $171 \mathrm{~cm}$, and her weight 84.6 kilograms. The sella tweica was not greatly enlarged (Fig. 29) and there were no local pressure signs. The basal metabolic rate was +24 per cent., though the thyroid was not palpable.

On May 10th, 1926, by the customary transphenoidal route a fairly radical removal of the glandular contents of the sella was accomplished by piluitary rongeurs and "sucker." The tissue operation there had taken place a marked diminution in the putfiness of the hands, the skin having become thinner, softer, and more pliant. To this the patient herself first called attention. This change was sufficiently marked to be shown photographically (Figs. 30, 31) as well as by actual measurement. Meanwhile, she had lost several kilograms in weight, and by the time of her discharge on June 3 rd he: basal metabolic rate had dropped twenty points, to +4 per cent.

She has, at the time of writing, remained free from headaches fer a year, and her hands and feet no longer feel stiff and swollen as they formerly did. The basal metabolism remains low.

Out of several, I may select another example of similas kind in which a well estahlished acromegaly: associated with a comparativoly small tumour has been for the time being banefited, not only subjectively but measurably.

(Surg. No. 27TT0.) A dentist, 47 years of agc, was admitted on December 8thr, 1926, becanse of severe cephalaigia. His headaches, which had begun in 1909, had steadily increased in severity until the pain with associated photophobia and attendant loss of sleep had completely incapacitated him from work. It was not until 1920 that he was suspected of having acromegaiy, but for several year's before then he had observed a progressive increase in the size of his head, hands, and feet. He formerly wore a $6 \frac{7}{8}$ hat and now requires a $7 \frac{3}{8}$ size; formerly a $7 \frac{1}{2}$ shoe, he now a 19 size. Mcanwlile, his wcight gradually increased now wears to $230 \mathrm{lb}$., and his hair had trened preternaty increased. from 148 married at the age of 25 and his only child is now 21 years old, the failure to have other children being ascribed to a cerriplete loss of libido.

In 1925 he was given a series of $x$-ray treatments, which at first greatly accentuated the headaches, but subsequently fave tcm-
porary relief. They, however, soon returned in their former porary relie

The clinical and roentgenological examinations on his hospital admission revealed typical advanced acromegalic changes. The skull (Fig. 32) showed the usual expansion of the frontal sinus, but the sella was only moderately enlarged, and ihere were no visual field defects. The basal metabolism on December 10th was +13 per cent.; the thyroid gland was not palpable.

The usual transphenoidal operation was done on December $16 \mathrm{th}$ with the double purpose of relieving, if possible, his headactie, and with the hope of at- the same time checking his hricrpituitarism. A soft tumefied gland was exposed, and a fairly radical though somewhat bloody extirpation was made of what proved histologically to be an acidophilic adenoma.

Four days after the operation both he and his wife called attention to the fact that his hands, previously stiff and puffy, had become supple, and that the skin was finely wrinkleci also that the skin of the forearms had become so loose and soft that it. could be picired up in folds. He tried an the snugly fitting gloves which he was accustomed to wear, and found that they slipped on with 'surprising ease, and felt actually loose. The same was true of his shoes.

A clinical note on December 23rd reads: " Patient states that not only are his hands smaller, so that he can see between the closed fingers for the first time he can remember, but the tactile acuity of the finger-tips has greatly increased. Whereas for years things have felt numb and indistinct, he can now distinguish, for example, the individual hairs of his shaven beard-a sensation he had almost forgotten was possible. His lips are unquestionably smaller, possibly his tongue, for he feels that his speech is much less thick than formerly."

His discharge note on December 31st reads: "Headaches have entirely disappeared. Patient's whole aspect greatly improved owing to loss of the puffy appearance of the tissues, previously so marked. There is actual wrinkling of the terminal pads of the fingers. Sweating, which was previously excessive, is much less than before. The basal metabolism has dropped from +13 ner
cent. on December 10th to -7 per cent. on December $3 c$ th. He has lost, meanwhile $2.5 \mathrm{~kg}$. in weight, in spite of a notable increase in his appetite.

On February 3rd, 1927, he wrote: "I have enjoyed my work more the past three weeks than I have in years. I have not missed have an uninterrupted night. I weighed $182 \mathrm{lb}$. before the operation in spite of my incippetence. I now weigh only $175 \mathrm{lb}$., though at each meal I eat more than double the amount I used to."

In both of these cases the evidences of acromegaly were full-blown at the time of operation, and yet in both there were post-operative indications of lessened glandular activity, if the loss of weight and the lowered hasal metabolism max be relied upon. As neithex of them showed any disturbance of carbohydrate metabolism; the sugar percentages could not be used as an additional measure of their improvement. Consequently one further example in which this test could be applied nay be called for.

(Surg. No. 25410.) An Italian woman, aged 22, married, was first admitted to the hospital on December 17th, 1925, complaining, among other things, of troublesome headaches. Previousiy in good health, she had married at 19; and a year later gave birth to a healthy living child, which she had nursed. On weaning the the time of her pregnancy she had never been free from headache, and had grown, as she expressed it " big' all over." Her features had becone coarse, her hands and fcet puffy, her skin hirsute, and, formerly slight, her weight had increased to $213 \mathrm{lb}$.

She had an enlarged and palpable thyroid and a basal metabolic rate of +25 per cent. There was also a slight glycosuria. bolic rate of +25 per cent. There was also a slight glycosuria.
She was looked upon as a possible case of acromegaly, but there She was looked upon as a possible case of acromegaly, but there
were some uncertainties about this, and as her sella lurcica was were some uncertainties about this, and as her sella lurcica was
not definitely enlarged (Fig. 33) she was given some general directions and referred to the ambulatory clinic.

Eight months later, August 27th, 1926, she was again sent into the hospital, because of continued cephalalgia, which had made her practically bedridden. Ffer basal metabolism was again found to be +25 per cent.; her blood sugar was 0.11 per cent.; and she showed glycosuria averaging daily from 0.7 to 0.8 per cent.

She was kept under observation for a month of ineffectual She was. kept under observation for a month of ineffectual
study. Shre might well enough have been regarded as having a polyglandular syndrome of some sort, not necessarily hypophyseal in origin, though, as a matter of fact, all hypophyseal disorders are polyglandular. On the basis of her increased metabolism and enlarged thyroid Lugol's solution was given a prolonged trial, but was finally decided that primary. hyperpituitarism could alone account for her symptoms, and, in spite of the small sella, it was proposed to operate, with the double purpose of checking her proposed to operate, with the double purpose of checking her subjective discomforts, if possible, and a
the constitutional effects of the disorder.

Accordingly, on September 20th, 1926, by the customary transphenoidal route a fairly radical extirpation of the sellar contents was made. The tissue proved histologically to be a typical chromophile adenoma.

She made an excellent operative recovery with immediate cessation of the headaches. Her glycosuria, which had been constiantly present during the pre-operative period of study, had disappeared
on the following day, and the urine remained sugar-free fors the on the following day, and the urine remained sugar-free fort the
next month while she was kept under observation. There was a coincidental drop in the blood sugar to below 0.1 per cent. Successive forty-eight-hour metabolism determinations showed a progressive fall from +25 per cent, on the morning of operation to +3 per cent. on September 30th, ten days afterwards, at which measured size of her hands; the previously wet and puffy skin mecame normally dry and supple. At the time of her disentarge, on October 20th, without dietary restriction, she had lost $3 \mathrm{~kg}$. in weight.

It is too soon, of course, to speak with any degree of finality of the effects of operations such as these have described, which at hest are carried out somewhat blindly in a deep and relatively inaccessible pocket. In comparison the removal of a thyroid adenoma is child's play; and without completely clearing out the content of the sella one cannot be sure that the fragments of adenomatous tissue almost inevitably left behind may not revive and produce further hyperpituitary symptoms. The very fact, however, that we may accomplish anything at all, even though the improvement be but temporary, is enongh to give us encouragement.*

\section{Conclusion.}

I confess that in the report of these few cases I have put $\mathrm{my}$ best foot forward so far as it concerns the influencing by operation of the secondary effects of hyperpituitarism. But I cannot belittle the extreme complexity of the surgical problem in a malady where symptoms are se bixarre and varied, and which is subject to spontaneous remissions.

* I have purposely refrained from mentioning deep radiation as an clternative to surgery in the treatment of an acromegalic adenoma. but it has not as yet come to take the place of operative procedures. 
How far we may safely go, how nearly we may venture to approach totality of extirpation of an acromegalic adenoma, time and experience only will tell.

We know from clinical experience, just as we have learned from the canine experiments of Camus and Roussy, of Bailey and Bremer, and from the experiences of Smith with the rat, that serious consequences ensue upon damage to the hypothalamic centre. It is a region. to be shunned lest diabetes insipidus, excessive adiposity, and even a fatal cachexia supervene. It is for this reason that operations for the congenital suprasellar cysts $I$ have spoken of are particularly difficult and hazardous. On the other hand, transphenoidal operations from below are even more blind, and there is the added risk of a cerebro-spinal rhinorrhoea and infection. Sometimes one, sometimes the other route is preferable. I am not here to plead for either, for this is a side issue on which surgeons, given time, will come to an agreement.

We have seen that there are an enormous number of secondary factors to be considered, which lie quite apart from the mere tumour and its pressure effects. That the hypophysis is primarily concerned with growth the brilliant studies of Evans and Smith that I have quoted leave unquestioned. No less definitely do these experiments show that it is an activator of the reproductive organs. Nature has provided that neither the pathological giant nor dwarf should reproduce his kind. These states, which necessarily originate in pre-adolescence, are represented by corresponding ones which set in later in life when normal skeletal growth has been attained. In these circumstances, too, for different causes apparently in the counterposed states of hypophyseal overaction and underaction, the functions essential to reproduction are interfered with. But this is only the beginning of a long sequence of alterations in other glands, affecting the thyroid and pancreatic islets in ways we partly understand, the parathyroids, adrenal cortex, and the rest in ways we do not.

Lastly, and not the least important, are the final stages in the two conditions of glandular insufficiency and overactivity : on the one hand the tissues atrophy with resultant senility and cachexia; on the other hand, splanchnomegaly and tissue hypertrophies are produced which, as in the case of the heart, lead to equally dire consequences. The surgeon who would operate on acromegaly must avoid the Seylla of the former in dodging the Charybdis of the latter. Not until some practical form of substitution therapy is at his call will he properly run the risk of overdoing his extirpation, for a daily homoplastic transplant so strikingly effective in the bypopituitary rat is out of his reach.

I have attempted in this address to bring some order out of the therapeutic chaos which envelops the subject of the pituitary disorders. Whether $I$ have succeeded does not particularly matter. Order will some day come, and the best that ean be done in the circumstances is to give hints in that direction. Hints, after all, may serve a useful purpose. Did not Lettsom so entitle as " Hints, Designed to Promote Benefieence, Temperance and Medical Science," a three-volume series of his suggestive articles? I was encouraged in the preparation of this address by one of his paragraphs, written on June $23 \mathrm{rd}, 1773$, proposing the establishment of : this Medical Society.

Many useful facts [he says] are lost from the want of a proper opportunity of eonveying them to the world; and though, when considered separately, they might not be of sufficient importance to claim the attention of the publick; yet when a number of them may be collected together, they may become highly deserving of notice. To such facts, when properly authenticated, the Society will always be particularly attentive.

And so, in respect to the memory of that industrious, suecessful, and many-sided man, your founder, if $I$ shall have given for your guidance the latitude and longitude of this "Little Vandyke" of Medicine, the pituitary body, somewhat more precisely, I shall be well content.

Reperences 8. Bailey, P., and Davidoff, L. M.: Amer. Journ. Path., 1925, i, 185-207.
9. Cushing, H., and Davidoff, L. M. : The Pathological Findings in Four Autopsied Cases of Acromegaly, with a Discussion of their Significance.
Monographls of the Rockefeller Institute for Hedical Research, No. 22,
April 23rd, 1927.

April 23 rd, 1927. io Partial Hypophysectomy for Acromegaly. Ainals of Surgery,
December, 1909,-p. 1003 .

\section{THE RATIONAL BASIS FOR TUBERCULIN THERAPY. \\ BY}

F. M. POTTENGER, M.D.,

SANATORIUM FOR DISEASES OF THE LUNGS AND THROAT, MONROVIA, California.

Now that we begin to understand the part played by the allergic inflammatory reaction in the healing of tubercle, tuberculin, which possesses the power of stimulating thit reaction, should come again to the fore as an important therapeutic measure.

It is now nearly forty years since Koch ${ }^{1}$ announced tc the world that he had discovered a "lymph" which possessed curative powers in tuberculosis. After the furore which followed the announcement had passed it was generally believed that the lymph had failed, but certain observers saw hope, for results were not uniformly bad. Healing did occur in certain instances. Members of the small group which was favourably impressed continued their studies and observations. Koch, while disappointed, did not despair. He knew that in the difference in reaction of animals toward first infection and reinfection lay the basis for a specific therapy for tuberculosis; and its attainment was of such great moment to a world which was yielding up one-seventh or more of its population to this disease that he persisted in his search in spite of all opposition.

\section{Tuberculosis Healed by Allergic Inflammatory Reaction.}

It is well to recall the observation whici caused Koch to believe in the possibility of a specific cure for tuberculosis. It follows his description of the difference in reaction of animals to first and successive inoculations of bacilli, either dead or living, as follows : ${ }^{2}$

"After I had observed this particular fact $I$ investigated it under every conceivable condition, and finally proved that dead cultures of tubercle bacilli rubbed up and mixed with water could be injected under the skin of healthy guinea-pigs in large doses without any effect beyond a local necrosis. (Those injecdoses without any effect beyond a local necrosis. (Those injec-
tions which were free from living bacilli were the simplest and surest means of producing necrasis.) Tuberculous guinea-pigs, on the other hand, were killed by the injection of relatively small quantities of such killed cultures, in from six to forty-eight hours, according to the size of the injection. A dose insufficient to kill the animal might produce an extensive necrosis of the skin at the point of inoculation. If the emulsion was diluted so that it was only slightly opaque then the animal remained alive, and if the injections were repeated with intervals of one or two days a injections were repeated with intervals of one or two days a
marked improvement in the condition took plaee; the ulcer at the marked improvement in the condition took place; the ulcer at the
site of inoculation became smaller and finally bealed, a thing site of inoculation became smaller and finally bealed, a thing
which never occurred without such treatment. The swollen lymph glands became smaller; the state of nutrition improved; and if the disease process was not too far advanced and the animal was rot losing strength too rapidly, a state of quiescence ensued. In these observations there is found a basis for a cure for tuberculosis."

The important part of this observation is that if the dose was sufficiently small, and if repeated at two-or threeday intervals, the animal not only remained alive but showed improvement. The ulcer at the site of inoculation hcaled-" "a thing which never occurred without such treatment."

The fact that tuberculosis heals itself by inflammation occurring as a result of allergic reaction called out by bacilli escaping from foci already existing within the host or from infections coming from without is now universally recognized. ${ }^{3}$. In natural infection immunity is built up by repeated reinoculations of bacilli, the source usually being the original focus or some successive focus produced from it. Immunity is built up in experimental animals by repeated inoculations with small numbers of bacilli, always short of the number necessary to cause uncontrollable infections. Fach infection that is overcome leaves the host with an increased resistance to future infections. Stimulation of unlealed foci previously existing is a part of the reaction following reinfection. It also follows the injection of bacillary protein. Uhthoff ${ }^{4}$ reported ten cascs of ocular tuberculosis treated by old tuberculin, when large doses were being used. He started with 0.5 or $1 \mathrm{nig}$. He produced violent focal and general reactions, and evein noted a spread of the disease in three instances, but all 